\title{
Balanço da educação escolar indígena no município de Dourados
}

\author{
Renata Lourenço Girotto*
}

Resumo: $\mathrm{O}$ artigo procura demonstrar alguns aspectos do processo de educação escolar indígena em Dourados, MS. De uma política educacional de caráter integracionista e disciplinadora, com vistas a garantir o prosseguimento do processo civilizatório de cunho capitalista, intentamse novas possibilidades de conquista da escola por parte dos indígenas, voltadas para projetos políticos de afirmação étnica. A experiência destes, especialmente na Reserva de Dourados, assume particularidades especiais porque ela se caracteriza como uma comunidade multiétnica, que abriga índios de três etnias, o que envolve disputas inter-étnicas, diferenças sócio-econômicas e culturais, que se manifestam de formas diversas na escola e requerem uma multiplicidade de estratégias para ampliar a capacidade de ação dos professores e da comunidade escolar como um todo.

Palavras chaves: educação escolar indígena; diversidade étnica; processo civilizatório.

\begin{abstract}
The aim of this essay is to show some aspects of indigenous school education in Dourados, MS. From an educational policy of an integrating and disciplining character, with the intention of guaranteeing the continuation of the civilizing process with the stamp of capitalism, new possibilities of conquest by the school on behalf of the indigenous members, focussing on political projects of ethnic affirmation are aimed at. This experiment, especially in the Dourados Reservation, takes on special particularities because it characterizes how a multiethnic community, which shelters Indians of three ethnic groups, which involves interethnic disputes, social, economic and cultural differences which are manifested in diverse ways in the school and require a multiplicity of strategies in order to amplify the capacity of action from the teachers and the school community as a whole.
\end{abstract}

Key words: indigenous school education; ethnic diversity; civilizing process.
* Professora de História da América e Prática de Ensino da Universidade Estadual de Mato Grosso do Sul. Doutoranda em História UNESP/Assis. renatagirotto@yahoo.com 


\section{Introdução}

A Constituição de 1988 inaugurou uma base de relações do Estado brasileiro com as populações indígenas no país, pautada em novos princípios, conferindo-lhes uma "[...] condição de cidadania, o que lhes garante juridicamente o direito de equidade e igualdade para viver sua diferença no que diz respeito à cultura, às tradições e aos costumes" (Nascimento et al., 2003, p.423). Em relação à educação escolar, foi garantido, pelo artigo 210, o uso das línguas maternas e de processos próprios de aprendizagem. Em decorrência dos princípios constitucionais, um novo e amplo quadro jurídico foi formulado para sustentar as iniciativas indígenas e de grupos de apoio - governamentais ou não - a fim de assegurar, na prática, as conquistas legais.

Em 1991, a responsabilidade da educação escolar indígena foi transferida da Fundação Nacional do Índio (FUNAI) para o Ministério da Educação - MEC (Decreto 26/91), regulamentada pela portaria interministerial 559/91, a qual definia como o MEC deveria atender às novas funções. O documento previa a criação de um comitê de Educação Escolar Indígena, formalizado em 1993, composto, inicialmente, por indigenistas que vinham atuando nacionalmente como assessores, pesquisadores, coordenadores e ministrantes de cursos junto aos movimentos de professores indígenas e Secretarias Estaduais e Municipais de Educação. Em 2005, esse Comitê foi substituído pela Comissão Nacional de Educação Escolar Indígena, composta de 15 membros, todos indígenas, representando as nações indígenas das cinco regiões do país.

As Diretrizes Gerais de Educação Escolar Indígena, formuladas em 1994, estabeleciam orientações no sentido de que a educação escolar indígena deveria ser "[...] necessariamente específica e diferenciada, intercultural e bilíngüe" (MEC, 1994, p. 12). Esses princípios orientam ou deveriam orientar, ainda hoje, as políticas públicas para as escolas indígenas, uma vez que se trata de fundamentos elaborados pelos próprios movimentos indígenas e indigenistas na luta pela conquista da escola.

A Lei de Diretrizes e Bases da Educação Nacional, de 1996, reafirmou o reconhecimento da necessidade da diferenciação em relação às demais escolas e consagrou o direito ao uso das línguas maternas e dos processos próprios de aprendizagem.

O Referencial Curricular Nacional para as escolas indígenas de 1998 ampliou e aprofundou os referenciais anteriores, acrescentando que a escola indígena deveria ser: "[...] comunitária, intercultural, bilíngüe/ multilingüe, específica e diferenciada" (RCNEI/MEC, 2002, p.24-25). 
Isto posto, o que significou a Constituição de 1988, bem como o quadro jurídico estabelecido após sua promulgação, para a educação escolar indígena no município de Dourados? Como as discussões promovidas pelo país afora se processaram no âmbito local?

Seja com base em diversas pesquisas de campo realizadas para fins de cumprimento das exigências do doutorado, ou como membro da equipe de educação escolar indígena da Secretaria Municipal de Dourados desde 2001, procuro evidenciar o processo vivenciado nas várias escolas do município que atendem majoritariamente crianças indígenas - dos pressupostos legais da educação escolar indígena à sua aplicabilidade, em âmbito local. Ainda me valho, principalmente, dos conceitos discutidos por Bartomeu Meliá (1978 e 1998) para referendar o meu próprio entendimento de uma educação escolar diferenciada, embora alargados por outras leituras (ver nota 2).

\section{Em busca do entendimento de uma educação escolar diferenciada}

Passar do plano teórico para o prático exige uma compreensão mais profunda do que tudo isso significa na escola, dentro da sala de aula. Como instrumentalizar técnicos e professores indígenas para a formulação e implementação de políticas que dêem conta de todas essas pretensões, uma vez que todo o aparato de organização das escolas teria que ser reformulado - currículo, avaliação, gestão, entre outros?

Muitas pesquisas sobre o assunto foram realizadas ${ }^{1}$, especialmente na área de educação. Estudos voltaram-se para a obtenção de dados sobre essa realidade em todo o país, como forma de melhor entender e intermediar o processo de educação escolar indígena junto aos órgãos competentes e às sociedades indígenas. Os próprios conceitos adotados ${ }^{2}$ foram alvo de muitas reflexões, uma vez que se sentia muito distante a teoria da prática.

Nas Diretrizes Gerais de 1994, era evidenciado que, por específico e diferenciado, compreende-se o respeito às características de cada escola, de cada comunidade, o que só surgiria a partir do diálogo, no compromisso e no envolvimento dos grupos indígenas como agentes e coautores de todo o processo. Por interculturalidade entende-se o intercâmbio positivo e mutuamente enriquecedor entre as culturas das diversas sociedades, o que significa passar de uma visão estática de educação para uma concepção que prime pelo dinamismo; significa também o estabelecimento e a manutenção de um diálogo constante entre as culturas, 
capaz de desvendar seus mecanismos, suas funções e sua dinâmica. O bilingüismo deveria ser pensado dentro de uma nova concepção, sendo o uso da língua materna, na alfabetização, não uma ponte transitória para o aprendizado do português, visando a incorporação do indígena à sociedade nacional, mas um código por meio do qual se organiza e se mantém integrado todo o conhecimento indígena e não-indígena acumulado ao longo das gerações. As melhores pedagogias reconhecem que o conhecimento de outras línguas, entre elas o português, torna-se mais natural e melhor incorporado por meio da língua materna, com o objetivo de ampliação dos conhecimentos e não como forma de supressão das línguas e culturas indígenas (MEC, 1994, p.10-12).

No Referencial Curricular Nacional para a escola indígena, formulado pelo MEC em 1998, reconheciam-se as contradições a serem superadas, uma vez que o cotidiano da maior parte dos povos indígenas " [...] desenvolve-se em um num contexto de tensão entre conhecimentos indígenas e ocidentais, entre políticas públicas e políticas de aldeias, entre tendências de políticas internacionais e a definição de estratégias e de opções específicas de vida e de futuro para as populações indígenas" (MEC, 1998, p.36).

Diante dos desafios propostos, buscou-se ampliar os debates no sentido de superar as contradições intrínsecas ao plano teórico e prático. O entendimento de uma escola diferenciada foi alargado por novos fundamentos teóricos, principalmente os de Meliá (1998) ${ }^{3}$, para quem o debate sobre uma educação escolar diferenciada não se estabelece nos limites estreitos de uma escola apartada, separada do mundo que a cerca. Ao contrário, coloca-a em contato com esse mundo, não como forma de suprimir a identidade étnica, mas como reafirmação e ampliação positiva dos referenciais culturais de que os indígenas dispõem em sua vida cotidiana e que nutrem a organização social de qualquer grupo humano.

A educação indígena tem origem em um movimento cultural interno e faz parte de um processo total em que a cultura é ensinada e aprendida segundo uma socialização integrante. A educação para o indígena percorre outro caminho como ponte para sua integração, primeiramente à sociedade colonial, por meio da catequização dos jesuítas, depois ao Brasil Imperial e Republicano, até recentemente. Meliá (1978) apontou para uma diferença básica entre os dois sistemas: "[...] enquanto a educação indígena se processa em termos de continuidade, a educação para o indígena pretende estabelecer a descontinuidade e a ruptura com o tempo anterior. A criança é tomada como tabula rasa" (Meliá, 1978, p. 53). 
E é esse processo de educação indígena que deve pautar a educação escolar. A cultura indígena deve ser a linha mestra da educação escolar, pois a educação indígena pode ser escolar e a educação escolar também pode e deve ser indígena.

Nesse sentido, a educação indígena deverá viabilizar um aspecto essencial da educação escolar, o bilingüismo, uma porta aberta (sem ser escancarada) para a entrada do conhecimento da sociedade não-indígena. É preciso convir que existe uma educação indígena prévia à escola, com muitos valores, e que ela é uma forma de entender o mundo, com palavras, gestos, ritmos, cadências com significados próprios, podendo e devendo ser integrada à escola.

A educação indígena precisa da escola, em razão de circunstâncias históricas advindas do contato e deve também conduzir essa escola. A Universidade, por seu lado, deve apoiar e fornecer subsídios para a capacitação dos indígenas, facultando-lhes a compreensão das novas condições, mas sempre com base nas raízes da educação indígena.

Por isso, a vocação da educação indígena na escola é ser bilíngüe. Esse bilingüismo não pode ser uma passagem só de ida, mas também de volta, para reafirmar a cultura, a identidade, a alma indígena. Só esse tipo de bilingüismo pode abrir espaços para um currículo diferenciado, o qual deve ser aplicado, fundamentalmente, nas primeiras séries, pois, à medida que se afirma e reafirma a língua, com todo o seu substrato cultural, afirma-se e reafirma-se também a identidade étnica. Quando a criança índia for para as escolas não-indígenas, ela estará em condições de entender melhor não só a língua portuguesa, mas de aprofundar-se de modo reflexivo em sua própria cultura.

Para que a linguagem escrita seja utilizada de forma positiva, é imprescindível que a política educacional se estabeleça sobre "[...] uma análise da situação lingüística da sociedade indígena. Em outros termos: a linguagem escrita não pode prescindir da realidade sociolingüística de cada grupo indígena que vai ser alfabetizado" (Meliá, 1978, p.64).

Essa realidade lingüística tem uma história, que “[...] não está desligada dos fatos sociais em que ela vive. A língua, que é uma representação do espaço vital, é também o modo de vivê-lo socialmente, com todas as suas mudanças históricas" (Meliá, 1978, p. 65).

É com base nessas discussões, ampliadas pelo próprio movimento de professores indígenas em atuação pelo Brasil, que me refiro ao modelo de escola diferenciada. E é pela necessidade de se conhecer a escola indígena "por dentro" que se faz urgente pesquisar situações particulares 
para que as ações, de fato, possam consagrar as especificidades de cada comunidade e de cada escola indígena.

\section{Breve contextualização histórica da educação escolar na Reserva de Dourados}

A Reserva Indígena de Dourados foi criada em 1917 para abrigar, inicialmente, índios Guarani. Somente em 1926, o Posto Francisco Horta seria construído. A partir de então, contou-se com uma política mais sistemática junto aos índios ali radicados. Ainda na década de 1920, chegariam as primeiras famílias Terena, incentivadas pelo Serviço de Proteção ao Índio (S.P.I.) com o objetivo de estimular a lavoura junto aos Kaiová pela reconhecida habilidade destes primeiros nessa atividade, bem como acelerar a integração daqueles junto à sociedade local. Assim, desde a década de 1920, a conformação populacional da Reserva é composta por três etnias: Guarani-Kaiová, Guarani-Ñandeva, Terena, e "mestiços" ${ }^{4}$ (entre índios e não-índios).

A primeira experiência de educação escolar junto aos índios da Reserva de Dourados aconteceu em 1929, em uma escolinha construída pelo S.P.I., realizada pelos missionários da Missão Evangélica Caiuá. Carvalho (2004) informa que, até 1937, o ensino junto aos índios da Reserva de Dourados teria sido desenvolvido pelos membros da Missão na escola do Posto, sendo que, até 1933, os esforços concentravam-se na alfabetização de adultos, cultos e a escola dominical, para, então, mediante os fracassos verificados, priorizar-se a alfabetização de crianças. Ainda em 1937, encontramos a informação de que teria sido construído, por aquela Instituição, um "[...] rancho no aldeamento barreiro secco [sic], destinado para escola" (Relatório Posto Indígena Francisco Horta, 9 de dezembro de 1937, Mf, fot. 170.), lugar mais ao centro da Reserva, onde se concentrava a maior parte dos índios da etnia Kaiová. Os objetivos eram os mesmos, o de aproximar e evangelizar estes índios, que eram considerados mais arredios ao contato. Essa escola teria funcionado até 1956, sob os cuidados da Missão, quando novas instalações teriam sido construídas pelo S.P.I. e assumido o ensino por ele.

Também em 1937, a Missão Evangélica Caiuá, que se estabeleceu nos limites da Reserva, próximo ao Posto do S.P.I., construiria a primeira escola, junto à sua sede, para atender as crianças do Orfanato recémconstruído. Dali em diante, a principal responsável pela educação escolar da população daquela Reserva seria a referida instituição religiosa. 
Desde a proclamação da República, várias tendências disputaram, palmo a palmo, a política indigenista oficial. Os primeiros indigenistas positivistas cobravam do governo federal que assumisse a proteção dos índios, em oposição à ação missionária. Essa posição derivava de uma estratégia política mais ampla que os positivistas reivindicavam para o Brasil, que pressupunha a adequação das relações sociais ao novo quadro institucional, que incluía o afastamento da Igreja Católica da esfera do poder. Daí a necessidade de secularização das práticas sociais. Pretendiam que fossem estendidos aos índios os direitos políticos burgueses instituídos com a República. Com a fundação do Serviço de Proteção aos Índios, em 1910, a corrente identificada com o Apostolado Positivista, em razão das novas condições históricas, passou a imprimir, na política indigenista oficial, uma fisionomia de "missão civilizadora", de caráter humanista e secular.

O processo civilizatório proposto inicialmente pelo S.P.I. foi sofrendo uma corrosão crescente, na busca de conciliar o que era inconciliável, colaborar com as frentes de expansão capitalista e, ao mesmo tempo, garantir a proteção dos povos indígenas e suas terras. No que tange ao propósito de secularização das práticas sociais, principalmente em relação à política educacional, a ação mostrou-se insignificante. Desde o início, diante da debilidade do Estado Republicano em promover as mudanças pretendidas, a Igreja Católica foi retomando os espaços nunca abandonados por completo. Só que essa disputa não seria mais tão somente com o Estado, mas com as Igrejas Evangélicas, que começam a se apresentar em várias regiões do país junto a inúmeros povos indígenas. O sul do então estado de Mato Grosso seria uma das regiões escolhidas pela Igreja Metodista e, depois, pela Presbiteriana.

Em razão de sua estrutura débil, o S.P.I. foi abdicando, paulatinamente, dos seus propósitos iniciais, e isso estaria bastante cristalizado quando de sua atuação junto aos povos indígenas do sul de Mato Grosso, tornando-se um colaborador de peso para as frentes de ocupação agropastoris. Ao mesmo tempo, promovia as condições para o avanço da atuação das instituições religiosas, especialmente nas questões de saúde e educação escolar, visando a civilização dos índios e sua incorporação à sociedade local.

Desde 1927, era revelado pelo S.P.I., em âmbito local, o caráter civilizador da escola:

[...] tomo a liberdade de recordar V. Exca. [sic] a conversa tida convosco da nomeação de minha esposa para a professora do Posto, uma vês estivesse esse em condições de pleno funcionamento e na altura de 
satisfaser o nobel programma [sic] a que Va. Ex. [sic] o destinou: a civilisação [sic] dos nossos índios (Ofício n. 21 de abril de 1928 confirmando relatório referente ao ano de 1927. Museu do Índio, Mf 194, fotograma 29/30; grifo nosso).

As solicitações repetir-se-iam em vários outros momentos, até que o ensino fosse assumido pela Missão Evangélica Caiuá, pois tal tarefa exigia colaboradores eficientes e esta se mostrava a mais apta, técnica e financeiramente falando.

Em 1937, era atestada a eficiência da Missão Evangélica Caiuá como parceira primeira do trabalho do S.P.I. junto aos índios da Reserva de Dourados:

[...] o que posso atestar sobre a referida missão é que ela vem prestando relevantes serviços, e possui medico, que atende os índios a qualquer hora, Engenheiro agrônomo que da aula de prática da agricultura aos Índios, Escola primária com freqüência de 16 a 18. Ministram cultos todos os domingos, fazem pregações dando bons conselhos que muito contribui para levantar a força moral dos nossos silvícolas, evitando muito o alcoolismo (Relatório Posto Indígena Francisco Horta, 9/12/ 1937, Mf 194, fot. 171).

Grande parte das funções do órgão indigenista oficial foi sendo repassada para a Missão, dando mostras de sua debilidade institucional, fato que se aprofundou nas décadas seguintes e se tornou marca indelével de seu caráter deformador, pretendido inicialmente como humanista e secular.

Assim, o processo de educação escolar patrocinado pelo Estado, pelo S.P.I., visto diacronicamente, foi se tornando bastante evidente: ao mesmo tempo em que se ia promovendo a concentração forçada dos índios habitantes da região sul do estado em Reservas, com o intuito de liberar vastas áreas de terras para a expansão das frentes de ocupação agropastoris, tentava-se uma política compensatória de cunho civilizatório, para a qual a escola poderia ser uma aliada importante. Dada a estrutura débil do Estado brasileiro, que se propunha a secularizar as práticas educativas, diante de suas limitações, este encoraja o estabelecimento das Missões religiosas como aliadas importantes na luta pela civilização dos índios, como forma de domesticá-los para o trabalho, num esforço conjunto de disciplinamento segundo as necessidades da empreitada capitalista no campo.

A escola apresentava-se como uma das medidas preconizadas para introduzir novos hábitos e novas necessidades, sendo que, simultaneamente, assistia-se à restrição das possibilidades de satisfazê-las. Sem condições de uma subsistência autônoma, vão-se estreitando os laços de 
dependência dos indígenas em relação às instituições religiosas e ao S.P.I., quando então se auto-liberam como mão-de-obra barata para as frentes de progresso monitoradas por este último. Ao mesmo tempo, são induzidos à conversão religiosa como forma de barganhar instrumentos - quinquilharias de toda sorte, roupas, calçados, remédios - para a satisfação de suas novas necessidades, estabelecendo uma relação de simbiose, usando e sendo usados, em um mecanismo frenético de usurpação progressiva da dignidade humana com relação aos índios.

Com essa situação estabelecida de submissão e dependência, a escola deixa de ser palco de maiores preocupações, e o Estado a assume tão-somente de maneira tangencial, mantendo-a em condições precárias, sem uma política efetiva para processá-la nem em atendimento às exigências capitalistas, e nem tampouco às necessidades das populações atendidas. $\mathrm{O}$ ensino é ministrado em português, os conteúdos não incorporam os conhecimentos indígenas, sem qualidade suficiente para ultrapassar os limites de uma educação formal, voltados apenas para uma alfabetização bancária, instrumentalizando somente para o domínio básico do ler, escrever e contar, com caráter absolutamente disciplinador.

Alguns conteúdos podem ser verificados em tarefas e/ou provas aplicadas em sala de aula durante os anos de 1965 e 1966, preservadas nos arquivos do S.P.I. Ressalto alguns trechos que me parecem bastante ilustrativos. Na área de português, mantinha-se mais ou menos a mesma estrutura de prova:

Cópia. O banho é indispensável ao asseio do corpo e a conservação da saúde. O banho diário constitui uma necessidade. As pessoas que tomam banho todos os dias se vêem dispostas para o trabalho, causando boa impressão com os quais convivem. O banho com água e sabão conserva a saúde e a limpeza. Banho todo dia dá saúde e alegria (Várias provas, junho de 1965. Museu do Índio, Mf 7, s/fot.).

Contrastando com as recomendações do texto, uma das maiores dificuldades registradas, desde o início da ocupação da Reserva de Dourados, foi a falta de água. Os poços furados logo secavam, provavelmente em razão dos lençóis freáticos naquela região estarem em camadas mais profundas da terra. Esse problema arrastou-se até recentemente (2005/ 2006), quando o Governo Federal, em razão da onda de mortes provocadas pela fome, denunciadas nacionalmente, promoveu o encanamento da água em toda a Reserva. De regiões normalmente ricas em rios, que estes povos costumavam habitar, foram trazidos compulsoriamente, sendo confinados em uma região como essa, para depois lhes serem difundidos os preceitos de uma ordem fincados nos princípios da 
"civilização" dos costumes que a cultura ocidental vai construindo para si e vai simultaneamente disseminando mundo afora, por meio do desenvolvimento capitalista.

No âmbito local, esse processo está relacionado à ocupação da terra por novos agentes do progresso. Aqueles dela desocupados teriam que passar por um processo de conversão, de modo a aceitarem pacificamente a mudança, a qual, no plano aparente, era-lhes apresentada como benesse do sistema.

Outros trechos ilustram novos preceitos:

[...] O trabalho enriquece, mas preguiça empobrece. [repetia-se várias vezes a mesma frase - de 8 a 10]

[...] Deus me guia à felicidade [repetia-se várias vezes a mesma frase]

[...] Jejum

Quem está em jejum isto é, quem não se alimenta pela manhã, torna-se fraco para os trabalhos do dia. Os alimentos podem ser de origem animal, como a carne, o leite e as aves; de origem vegetal, como os legumes, as verduras e as frutas; e de origem mineral, como o sal de cozinha, com que temperamos as comidas. Sem alimentação não há vida. Quem sabe alimentar-se tem saúde e vontade de trabalhar. Quem se alimenta mal, perde as forças, fica doente, impossibilitado de trabalhar (Várias provas, 1966. Museu do Índio, Mf 6, planilhas 82 a 90).

É irrefutável a preocupação com a disciplina no trabalho, reforçando todas as teses sobre os objetivos reais da educação escolar difundida junto aos povos indígenas do país, reproduzida em todos os rincões por onde acontecia a atuação do S.P.I. e das instituições religiosas; não raro, eram os índios disfarçadamente responsabilizados pelo seu fracasso, impedindo eles próprios a sua "evolução" na escala civilizatória.

A política educacional implementada junto aos índios da Reserva de Dourados prosseguiu nas décadas seguintes, sendo inclusive intensificada pela FUNAI, que assumiu um caráter autoritário com o regime militar implantado no país após 1964.

Contudo, em outra dimensão, observamos, cotidianamente, por parte dos indígenas, mecanismos sublineares de contraposição à ordem estabelecida, que vão fomentar um amplo movimento indígena e indigenista nas décadas de 1970 e 1980, voltado para o redimensionamento da política oficial, o que definiu um campo político capaz de inferir decisoriamente no processo da Assembléia Constituinte, resultando nas conquistas da Constituição de 1988.

No início da década de 1980, na região sul do estado, foi registrada uma primeira experiência de educação alternativa oferecida pelo CIMI 
em parceria com antropólogos que desenvolviam um trabalho no município de Caarapó, conhecido como Projeto PKN (Projeto Kaiowá/ Nandeva), no qual desenvolviam ações voltadas para a preparação de lideranças na área de subsistência, da terra e da organização política, incluindo aí a área de educação escolar. Foi realizada a alfabetização, em português, de um grupo de mulheres, que depois se estenderia para novos grupos. O CIMI promoveu, em 1986, o primeiro encontro de representantes e lideranças Guarani para discutir, especificamente, a educação escolar. A partir do ano seguinte, reuniões de professores foram realizadas nas dependências do CIMI para se refletir sobre a realidade das escolas nas aldeias do estado e sobre as possibilidades de superação dos problemas advindos de um modelo de escola alheio aos interesses das comunidades. Essas ações fundamentariam um primeiro esboço para a organização de professores indígenas Guarani do estado.

Em resposta às novas condições legais, pós-Constituição, o Movimento de Professores Guarani organizou-se para buscar fundamentação teórica para respaldar a prática da educação escolar, agora sob novos paradigmas. Em 1991, aconteceu o I Encontro de Professores e Lideranças Guarani, em clima de muita desconfiança, pois, para muitos, uma educação diferenciada significava um retrocesso. Para outros, apontava-se para novas possibilidades de organização do movimento, com vistas a se avançar no processo de conquista da escola. No relatório final do Encontro, ficou registrado que:

[...] a comunidade deve decidir o que vai ser ensinado na escola, como vai funcionar e quem vão ser [sic] os professores.

A nossa escola deve ensinar o Nande Reko (nosso jeito de viver, nossos costumes, crenças, tradição, nosso jeito de educar nossos filhos, de acordo com nosso jeito de trabalhar e com nossa organização). Para isso precisamos ensinar na nossa própria língua guarani. Mas precisamos também aprende alguma coisa do branco (português, como segunda língua, as leis e outras coisas que nos interessam).

A sustentação da escola indígena deve ser garantida pelo Governo e pela comunidade.

Os professores podem receber capacitação e assessoria dos brancos que oferecem este tipo de trabalho.

Apesar de ter sido um encontro patrocinado pelo CIMI e de ter a mediação direta de seus missionários na elaboração do documento, este refletia as aspirações de parte dos participantes. Muitos deles não tinham clareza sobre o teor das discussões, mas referendaram as propostas. Durante toda a década, esses encontros se repetiram, patrocinados e/ou apoiados por novos parceiros: Universidade Federal de Mato Grosso do 
Sul, Governo do Estado, entre outros, ampliando a participação quantitativa e qualitativamente dos professores e lideranças, atingindo, paulatinamente, direta ou indiretamente, todas as escolas das aldeias com população Guarani do estado, inclusive a de Dourados.

\section{As respostas do sistema Municipal de Educação do Município de Dourados aos imperativos legais}

A atuação direta do S.P.I., depois FUNAI, na área educacional na Reserva de Dourados, manteve-se restrita à Escola Francisco Ibiapina, até fins da década de 1970. Em 1979, foi construída a Escola Araporã, pela FUNAI, com duas salas de aulas, e, em 1984, uma salinha denominada Agustinho, em parceria com a Missão Evangélica Caiuá, usada também como Igreja.

Em fins da década de 1980, as escolas mantidas pela FUNAI atendiam aproximadamente 250 alunos, segundo estimativa da Secretaria Municipal de Educação. Não foram encontrados registros do número de alunos atendidos pelas escolas da FUNAI desde fins da década de 1960 até início da década de 1990. Em contrapartida, a Missão Evangélica Caiuá continuava a atender uma parte significativa da demanda escolar da Reserva de Dourados. Em 1973, a escola seria transformada em Escola Primária, assumida pela Prefeitura em parceria com a Missão, sendo esta a responsável pela parte pedagógica e a primeira pela manutenção financeira. Em 1980, a escola passou a atender alunos da $1^{\mathrm{a}}$ à $8^{\mathrm{a}}$ série $^{5}$. Em 1990, atendia 259 alunos, ou seja, a mesma capacidade de atendimento das escolas mantidas pela FUNAI.

Atualmente, o município de Dourados possui duas áreas indígenas - a Reserva de Dourados e a Terra Indígena do Panambizinho. A primeira foi criada em 1917 e a segunda, depois de um longo processo de litígio, foi reconquistada e homologada em dezembro de 2004.

A Reserva de Dourados localiza-se a $10 \mathrm{~km}$ do centro da sede do município e é ocupada por uma população estimada em aproximadamente 11 mil indivíduos, segundo a Fundação Nacional de Saúde (FUNASA, 2006), convivendo em uma área de 3.539 hectares. A Terra Indígena do Panambizinho localiza-se a $30 \mathrm{~km}$ do centro da cidade e possui uma população de aproximadamente 280 habitantes, somente da etnia Guarani-Kaiová.

Os alunos indígenas do município são atendidos, atualmente, em sua totalidade, pelas escolas: 1) Escola Municipal Tengatuí Marangatú, 
que possui 4 extensões - Ibiapina, Salas do Ensino Médio, Sala Y’Verá e Sala Marangatú, esta última a 30 km,em Passo Piraju, uma área em litígio; 2) Escola Municipal Indígena Araporã; 3) Escola Indígena Agostinho (com exceção da sala Marangatú, todas se encontram dentro dos limites da Reserva de Dourados); 3) Escola Municipal Indígena Pai Chiquito - Chiquito Pedro, na Terra Indígena do Panambizinho; 4) Escola Municipal Francisco Meirelles, em parceria com a Missão Evangélica Caiuá, que atende majoritariamente alunos indígenas e se localiza nos limites externos da Reserva de Dourados.

Atendendo às determinações legais estabelecidas pelo Decreto 26/ 91, que transferiu a responsabilidade da educação escolar da FUNAI para o MEC, em 1992, foi assinado um Termo de Convênio entre a FUNAI e Prefeitura Municipal de Dourados, visando ao funcionamento e à manutenção do Centro de Educação Unificado Tengatuí Marangatú e das escolas Araporã, Agustinho e Panambizinho. A demanda atendida pela escola Francisco Ibiapina seria incorporada pela Escola Tengatuí, recémconstruída. Ainda no mesmo ano, esta última seria transformada em escola-pólo, abrigando as demais escolas como salas-extensão, nos moldes das escolas rurais. A capacidade de atendimento foi ampliada, sendo registrado, naquele ano, a matrícula inicial total de 618 alunos de $1^{\text {a }}$ a $4^{\text {a }}$ série, contra 292 da escola Francisco Meireles (Dados, SEMED, 1992). O atendimento de $5^{\mathrm{a}}$ a $8^{\mathrm{a}}$ série, dentro das escolas da Reserva, aconteceria somente a partir de 2004.

Entre 1993 e 1996, a Universidade Federal de Mato Grosso do Sul/ Dourados ofereceu um curso de capacitação, em nível de primeiro grau, aos professores Guarani do estado, em parceria com a Secretaria de Estado de Educação e municípios, FUNAI, e organizações não-governamentais, no caso o CIMI (Conselho Indigenista Missionário) e a Missão Evangélica Caiuá. Tratava-se da primeira experiência governamental voltada para a formação específica de professores indígenas no estado. Concomitantemente, a SED buscava promover debates internos nas escolas indígenas do estado, em parceria com as Secretarias Municipais de Educação.

Em 1996, o Conselho Estadual de Educação, pela primeira vez, regulamenta a organização de uma escola indígena com regimento, quadro curricular e calendário escolar diferenciado.

Naquele mesmo ano, na escola Tengatuí Marangatú, aconteceu um debate sobre as possibilidades de se implementar um projeto de ensino bilíngüe. As discussões foram fruto, direta ou indiretamente, do Movimento de professores Guarani e/ou do próprio processo de formação que a 
Secretaria de Educação do Estado, juntamente com as Secretarias Municipais, passou a promover em várias aldeias, inclusive em Dourados, desde 1993. A ação da SED previa fundamentar/instrumentalizar os professores, índios e não-índios, quanto à importância do ensino bilíngüe em atendimento, ainda que embrionário, ao preconizado pela legislação específica para a Educação Escolar Indígena no estado (Diretrizes Nacional e Estadual, e Deliberação/CEE n. 4324/95). Ocorreu que a discussão, processada pelas agências formadoras, fomentou disputas internas em um clima de tensão que resultou na negação do projeto. Segundo consta no documento enviado pela Secretaria Municipal de Educação para o Conselho Estadual, justificando a não inserção do ensino bilíngüe no Regimento Escolar segundo suas recomendações, a escola apresenta os seguintes motivos:

[...] agravaria as diferenças culturais entre as nações e, consequentemente, os problemas internos da Reserva Indígena; dificultaria, para a comunidade indígena, a inter-relação e a convivência com a sociedade envolvente; dependeria, para a realização com qualidade do ensino bilíngüe, do aprendizado das línguas Guarani e Terena nas suas formas falada e escrita - pelos professores que não têm esse domínio.

Logo, não se alcançou os objetivos das capacitações realizadas desde 1993 e, o ensino bilíngüe não pôde, ainda concretizar-se, o que demonstra a necessidade de se continuar investindo em ações voltadas para essa finalidade, na tentativa de reverter o quadro acima descrito.

Dourados, 05 de maio de 1997.

O conteúdo do documento nos conduz a várias considerações. Em primeiro lugar, a escola era administrada por professores de maioria Terena e não-indígenas (de um total de 24 professores, 11 eram Terena, sete não-índios e seis Guarani), que exerciam forte controle da escola e sua prática educacional. Os Terena, em sua maioria, não mais dominam a língua indígena, sendo o português sua língua materna; juntamente com os professores não-indígenas, não apresentavam, de fato, condições de processar o ensino bilíngüe. Por outro lado, os professores Guarani, apesar de falarem a língua materna, não a dominavam em sua forma escrita, fato que, aliás, marca o rol de dificuldades ainda hoje enfrentadas nas escolas que atendem a população dessa etnia. Há ainda que se considerar que os Terena e Guarani são descendentes de culturas absolutamente diferentes, constituindo universos simbólicos díspares, apresentando práticas e representações substancialmente diferenciadas. Isso significa que a representação que cada um desses grupos tinha/tem sobre a escola é muito distante uma da outra.

O projeto político pedagógico da escola tem que garantir, na prática educativa, as especificidades de cada grupo, sem detrimento um do outro. 
Isso requer muita preparação, subsídios teóricos e práticos que terão que ser fomentados pelas agências educacionais, em uma política sistemática de formação continuada, e pelas Universidades, na formação inicial desses professores, situação inexistente na época e ainda em vias de concretização.

Outro aspecto importante a se destacar são as justificativas apresentadas para a negação do ensino bilíngüe, mas que hoje assumem novas dimensões. Em primeiro lugar, temia-se agravar as diferenças culturais. Como pensar isso e reformular o projeto pedagógico da escola, no sentido de reorganizá-la de maneira a garantir a convivência, sem prejudicar uma parte considerável dos alunos, em sua maioria Guarani, seja da etnia Kaiová ou Ñandeva? Sob que ponto de vista isso foi colocado? Não seria possível construir um projeto pedagógico de forma a contemplar as diferenças sócio-linguísticas sem prejudicar o convívio social entre as várias etnias? Essas são premissas importantes para estimular as discussões e promover a superação das divisões internas ainda existentes.

Outro motivo apontado era o de que se dificultaria a relação com a sociedade envolvente. Esse é o grande ponto que divide opiniões até hoje. Parte dos próprios Guarani defende a eliminação do ensino bilíngüe na escola, porque, na perspectiva de um futuro de convivência com a sociedade não-indígena, está sedimentada a idéia de que o domínio do português pode garantir maior aceitação, tanto social quanto profissional. Desconsiderando-se o conhecimento sobre o desenvolvimento cognitivo da criança, que orienta para a alfabetização em língua materna, o ambiente da escola fica ainda mais tenso; para além das diferentes concepções acerca do processo de educação, existe uma rede de disputas entre as várias etnias e entre grupos, visando ao controle da escola, a qual passou a constituir um novo espaço privilegiado de poder.

Isso, contudo, deve ser bem dimensionado, porque, atualmente, uma boa parte dos professores Terena defende uma escola indígena diferenciada em todos os seus aspectos, enquanto muitos Guarani ainda não o fazem, por temerem uma volta no tempo em relação às possibilidades de domínio do português, fato que está enraizado no imaginário de uma boa parte dos pais e professores, como condição para se abrir as portas da sociedade envolvente. As disputas étnicas podem ser diluídas consideravelmente, na medida em que os debates em torno do processo de alfabetização forem melhores qualificados e o diálogo interétnico for intensificado.

Finalmente, a falta de domínio da língua na sua forma escrita era, de fato, um grande empecilho e ainda hoje se apresenta como uma grande dificuldade, mesmo para os Guarani, os quais, sem dúvida, avançaram 
bastante; mas a falta de um código escrito da língua Guarani regional, com definições mais claras do Kaiová e do Nandeva, ocasiona vários embaraços na escrita. A formação lingüística deverá propiciar uma maior clareza sobre as proximidades e as diferenças entre ambas, a serem superadas e/ou reconhecidas como algo positivo.

Contudo, o que torna a situação mais complexa é pensar essas línguas em todo o seu substrato cultural e histórico. Faltam pesquisas que sistematizem os conhecimentos indígenas que são parte fundamental do bi/multilinguismo a ser desenvolvido nas escolas. Sem isso, poderá ocorrer um esvaziamento cultural da língua, o que prejudicaria o papel da escola em promover a interculturalidade, ou seja, dialogar com as culturas envolventes, mas sem perder de vista que a cultura indígena é o ponto de partida e de chegada, porque é a partir dela que os povos indígenas se organizam.

Somente em 1999 aconteceria, efetivamente, a primeira experiência de ensino diferenciado. No projeto, consta a reflexão de alguns professores acerca das dificuldades dos alunos que chegavam falando o Guarani e que, por isso, tinham que dar novas respostas para o problema. Assim, estabeleceu-se que a escola iria começar a experiência em 6 salas de aula, entre pré-escolar e $1^{\mathrm{a}}$ série (uma sala de pré-escolar na Tengatuí - pólo; uma sala de pré-escolar na extensão Agostinho; três salas da 1a . série na Escola Araporã e uma sala de $1^{a}$ série da extensão $Y^{\prime}$ Verá). A partir de 2000, desenvolver-se-iam, em " [...] todas as salas da escola pólo e extensões estudos por temas gerados e a interdisciplinaridade dos currículos. O resgate das histórias da comunidade por escrito foi uma das preocupações dos professores e ficou com a parte diversificada do currículo da Tengatuí" (Projeto Ensino Diferenciado, Escola Tengatuí, s/p, 1999).

A ampliação e dinamização das discussões tornou possível esse processo. O Projeto de Magistério Específico de professores Guarani, oferecido pelo Governo do Estado a partir de 1999 e a assessoria da Universidade Federal de Mato Grosso do Sul, por intermédio da professora Adir Casaro Nascimento do Departamento de Educação, foram fundamentais para alavancar o processo naquela escola. Em 2000, a experiência foi estendida para mais 5 salas de aula. Em 2005, contava-se com 24 salas.

Em 2001, a Secretaria Municipal de Educação de Dourados criou uma gestão de processos de educação escolar indígena, atrelada à coordenadoria do Ensino Fundamental, sob a liderança, inicialmente, de uma professora Guarani, a qual, dois anos depois, passou a contar com a colaboração de uma professora Terena, ambas formadas em pedagogia. 
No plano administrativo, aconteceu a reforma/ampliação e construção de novos espaços nas escolas existentes, como secretarias, cozinhas, banheiros, pátios cobertos, entre outros, com o aparelhamento mínimo exigido, como a extensão da rede de energia elétrica, compra de freezers para armazenamento da merenda escolar e novos conjuntos escolares. Tal estrutura ainda é deficitária, quantitativa e qualitativamente, mas representou um avanço significativo.

No plano pedagógico, o processo de Constituinte escolar desencadeado pela Secretaria Municipal de Educação de Dourados (SEMED, 2001 e 2002) proporcionou um amplo movimento de discussão no interior de todas as Escolas e Centros de Educação Municipais, inclusive nas escolas e extensões indígenas, possibilitando a participação de todos os segmentos da comunidade escolar: pais, alunos, professores, diretores, coordenadores e demais funcionários administrativos. A Constituinte caracterizou-se por um longo processo de reflexão coletiva, problematizando a escola que se tinha e a escola que se queria, gerando oportunidade para um grande momento de avaliação das práticas pedagógicas, evidenciando situações de conflito e problemas existentes na escola. Cada escola apresentou uma visão própria de sua realidade particular. Entre os vários problemas evidenciados, um dos mais graves residia na inadequação dos currículos, o que resultou na reorientação curricular de todas as escolas da Rede.

Na nossa avaliação, as escolas indígenas foram as que melhor corresponderam às propostas apresentadas, juntamente com algumas escolas rurais. A proposta caracterizava-se por uma metodologia que previa garantir no currículo a realidade do aluno, a fusão da visão do educador e a da comunidade, de conhecimentos da educação formal, sistematizados historicamente e conhecimentos populares. A proposta previa atingir a dimensão social do currículo, o que pressupunha garantir a interdisciplinaridade como estratégia fundamental para o êxito da metodologia, pois só assim se poderia enfrentar o problema da fragmentação do conhecimento. Esse elemento tem sido o que mais desperta interesse nos professores indígenas que têm seu universo simbólico construído na totalidade da realidade envolvente. Neste ano de 2006, iniciou-se a experiência de construção de redes temáticas na língua Guarani.

Concomitantemente, eram discutidas as possibilidades de criação da categoria de escola indígena no âmbito do sistema municipal de ensino, bem como da criação de escolas indígenas regulamentadas como tais. Em cada escola, era debatido o assunto, sendo que cada uma delas apresentou respostas diferenciadas e próprias. A extensão do Panambizinho foi a primeira a se pronunciar favoravelmente à criação de escola indígena, 
primeiramente, em razão da possibilidade de se tornar uma escola autônoma, independente da escola-pólo. Uma outra razão que se mostrava bastante evidente era a preocupação que a comunidade tinha em revitalizar e fortalecer a cultura por meio da escola, uma vez que vivia sob o impacto da luta pela retomada da terra, fato que se concretizaria em fins de 2004. Todos ali são da etnia Guarani/Kaiová, e a aspiração por uma escola autônoma era muito antiga. Naquele momento, a possibilidade de ser essencialmente Kaiová suscitou muita empolgação e envolvimento de grande parte da comunidade: lideranças, professores, pais e alunos. As divergências internas na escola foram superadas, não sem conflitos, sendo registrado que um casal de professores teve que se retirar da escola para que o processo pudesse ter continuidade, segundo o direcionamento dado por algumas lideranças, visando o controle da escola.

Assim foi que, em consonância com as aspirações, primeiramente dessa comunidade, com as determinações legais e a indicação do Conselho Municipal de Educação (Indicação n. 001/2003), foi criada a Categoria de Escola Indígena no âmbito do Sistema Municipal de Ensino de Dourados, através do Decreto 2442, de janeiro de 2004. Na mesma data, seria criada a primeira escola indígena no município, que passou a ser denominada de Escola Indígena Pai Chiquito - Chiquito Pedro, pelo Decreto 2444, na Terra Indígena do Panambizinho.

Em seguida, vieram as solicitações das escolas Agostinho e Araporã para se tornarem escolas indígenas, o que foi atendido pela SEMED. A primeira foi transformada em escola indígena através do Decreto 3195, de 01 de outubro de 2004, e a segunda através do Decreto 3395, de 22 de dezembro de 2004. Todo o processo de discussão realizado no Panambizinho, visando a organização administrativa e pedagógica da escola, foi garantido nas escolas da Reserva de Dourados.

Por último, foi criada a Lei n. 097, de 06 de junho de 2006, que estabeleceu os cargos de profissionais do Magistério Indígena. O Edital de Concurso para o preenchimento de vagas desses cargos (n. 001-B2006, de 29 de junho de 2006) obedeceu às determinações da referida lei e garantiu o número de vagas por etnia, obedecendo a proporcionalidade do número de população de cada uma delas existentes na Reserva. $\mathrm{O}$ mesmo procedimento de distribuição das vagas por etnia já havia sido contemplado no Concurso Público para o Quadro Administrativo das Escolas Indígenas (Edital n. 001/03 - SEMAD, de 03 de julho de 2003).

Várias reuniões foram promovidas pela SEMED, quando os vários segmentos da escola eram agrupados separadamente - pais, alunos, funcionários administrativos e professores, visando garantir a participação 
de todos, de forma que nem um nem outro se sentisse inibido para se expressar. No final de cada reunião, eram socializadas as questões levantadas sobre quais os problemas que enxergavam na escola e como pensavam em resolvê-los, bem como eram apresentadas as propostas, como, por exemplo, o oferecimento da segunda fase do ensino fundamental, de $5^{\mathrm{a}}$ a $8^{\mathrm{a}}$ série, reivindicação de todas as escolas, e que suscitou várias polêmicas, mas que, levada à votação em plenária, acabou sendo aprovada por unanimidade pelos pais e por isso mesmo prontamente atendida pela SEMED. Outras problemáticas como a eleição dos coordenadores de cada escola e o que eles deveriam fazer seguiam a mesma metodologia.

Os problemas mais citados por todos os segmentos foram: a violência, alcoolismo, drogas ilícitas (maconha), brigas familiares e a dificuldade dos alunos de idade mais avançada permanecerem na escola, por terem que trabalhar fora da Reserva. Várias proposições foram feitas no sentido de que a escola promovesse atividades educativas complementares e profissionalizantes, o que resultou na elaboração de um projeto em torno de atividades múltiplas, como da roça Kaiová no Panambizinho e a construção de um viveiro na Escola Araporã, visando à produção de mudas de árvores nativas e frutíferas para o reflorestamento de algumas áreas da Reserva. O projeto prevê outras atividades na área de esportes, informática, artesanato, entre outros. Está em fase inicial de implantação, transcorrido em meio a muitas dificuldades, exigiu muito empenho, principalmente, da comunidade escolar.

Em 2005, a escola-extensão Francisco Ibiapina já se manifestava pela criação de uma escola própria. Contudo, em razão de infra-estrutura e de estudos mais detalhados, que estão sendo realizados pela SEMED sobre o fluxo interno de alunos de uma região para outra, tudo parece apontar para a inadequação daquela escola no lugar atual. Os dados indicam que a Escola deveria ser transferida para a área da Bororó, porque grande parte dos alunos é dessa localidade, o que evitaria o transporte escolar por maiores distâncias e garantiria mais conforto aos alunos.

Já a escola Tengatuí-pólo, apesar de estar galgando degraus importantes na escalada para a construção de uma escola que corresponda mais aos anseios da comunidade indígena, trabalhando um currículo diferenciado, participando de todos os processos de discussão, ainda não se manifestou favorável a uma escola propriamente indígena, mesmo que em âmbito formal. Entendemos que as razões estejam na própria diversidade étnica, tanto de alunos quanto de professores e por condições históricas, pois ali foi praticada uma política de educação escolar 
com forte base conceitual da escola tradicional não-indígena. Sabemos que mudar representações e práticas educativas, mexer em situações de poder cristalizadas não é tarefa das mais fáceis, seja em que escola for.

Assim, todo o processo de discussão desencadeado no interior dessas escolas tem propiciado avanços significativos em termos de participação, ainda que lentamente, mas em bases sólidas.

O número de alunos cresceu consideravelmente, e estes são atendidos, atualmente, nas várias escolas apresentadas no quadro a seguir:

Quantitativo de alunos das escolas indígenas

\begin{tabular}{|l|r|r|r|r|r|r|r|}
\hline \multirow{2}{*}{ Escola municipal } & \multicolumn{7}{|c|}{ Número de alunos } \\
\cline { 2 - 8 } & \multicolumn{1}{|c|}{1992} & 1993 & 1994 & 1995 & \multicolumn{1}{|c|}{1996} & 1997 & \multicolumn{1}{|c|}{1998} \\
\hline EM Tengatui Marangatu - Pólo & 618 & 688 & 621 & 615 & 729 & 786 & 983 \\
\hline EMI Francisco Meireles & 291 & 278 & 274 & 260 & 272 & 269 & 531 \\
\hline TOTAL & $\mathbf{9 0 9}$ & $\mathbf{9 6 6}$ & $\mathbf{8 9 5}$ & $\mathbf{8 7 5}$ & $\mathbf{1 0 0 1}$ & $\mathbf{1 0 5 5}$ & $\mathbf{1 5 1 4}$ \\
\hline
\end{tabular}

Fonte: Atas de resultados finais até 1996. Os censos escolares de 1997 e 1998 não eram sistematizados nos moldes atuais. Não se forneciam números de alunos por extensão.

Pode-se observar, nesse período de 6 anos, que o número de alunos indígenas chegou a aumentar em 605 , atingindo um crescimento na ordem de $66,4 \%$, uma média anual de $11,6 \%$.

\begin{tabular}{|l|r|r|r|r|r|r|}
\hline \multirow{2}{*}{ Escola Municipal } & \multicolumn{6}{|c|}{ Número de alunos } \\
\cline { 2 - 7 } & 2000 & 2001 & 2002 & 2003 & 2004 & 2005 \\
\hline EM Tengatui Marangatu - Pólo & 651 & 723 & 617 & 721 & 659 & 641 \\
\hline - Extensão Francisco Hibiapina & 170 & 177 & 294 & 276 & 300 & 288 \\
\hline - Extensão Sala Marangatu & - & - & - & - & 14 & 13 \\
\hline - Extensão Yvera & 17 & 12 & 24 & 30 & 29 & 38 \\
\hline - Extensão Ensino Médio & - & - & - & - & 92 & 114 \\
\hline EMI Agustinho & 101 & 121 & 160 & 161 & 223 & 304 \\
\hline EMI Araporã & 110 & 110 & 119 & 151 & 184 & 265 \\
\hline EMI Pai Chiquito - Chiquito Pedro & 60 & 68 & 60 & 53 & 76 & 93 \\
\hline EM Francisco Meireles & 687 & 683 & 773 & 855 & 895 & 877 \\
\hline TOTAL & $\mathbf{1 . 7 9 6}$ & $\mathbf{1 . 8 9 4}$ & $\mathbf{2 . 0 4 7}$ & $\mathbf{2 . 2 4 7}$ & $\mathbf{2 . 4 7 2}$ & $\mathbf{2 . 6 3 3}$ \\
\hline
\end{tabular}

Fonte: Censo Escolar 2000, 2001, 2002, 2003, 2004 e 2005.

Acrescentando-se os dados da matrícula inicial de 2006, logo adiante, verifica-se que o número de alunos indígenas atendidos pela Rede Municipal de Dourados foi de 1139 alunos, um acréscimo de 65\% em 6 anos, significando uma média anual de 10,8\%. Em 12 anos, a média de matrícula vem se mantendo em níveis elevados. Contudo, esse aumento do acesso 
escolar não se traduz no término dos estudos da última fase do ensino fundamental. No ano de 2005, foram registrados somente 59 alunos matriculados na $8^{\text {a }}$ série (Censo escolar SEMED, 2005), o que impõe a necessidade de políticas mais consistentes para garantir a permanência do aluno indígena na escola, motivo para considerações em outra oportunidade.

Em 2006, os dados da matrícula inicial, levantados para o censo escolar, levaram em consideração a origem étnica dos alunos. Isso significa um grande avanço, porque cria condições para uma melhor organização da escola. Os dados propiciam maior nitidez com relação às diferenças socioculturais e lingüísticas. A continuidade da presente pesquisa inclui a análise da produtividade escolar também por etnia, tendo em vista verificar se há diferença de rendimento entre os vários grupos e, se houver, quais as razões: barreira lingüística, fatores de ordem cultural, entrosamento na escola, relacionamento com os professores, inadequação dos currículos, avaliação, formação dos professores, entre outros.

\begin{tabular}{|c|c|c|c|c|c|c|c|c|c|c|c|c|}
\hline \multirow{2}{*}{$\begin{array}{l}\text { Escola } \\
\text { Municipal }\end{array}$} & \multicolumn{12}{|c|}{ Número de alunos em relação à origem étnica } \\
\hline & 1 & 2 & 3 & 4 & 5 & 6 & 7 & 8 & 9 & 10 & 11 & Total \\
\hline $\begin{array}{l}\text { Francisco } \\
\text { Meireles }\end{array}$ & 190 & 226 & 310 & 27 & 73 & 3 & 1 & 7 & 55 & 2 & 7 & 901 \\
\hline $\begin{array}{l}\text { Indígena } \\
\text { Agustinho }\end{array}$ & 340 & 33 & 9 & & & & & & & & & 382 \\
\hline $\begin{array}{l}\text { Indígena } \\
\text { Araporã }\end{array}$ & 308 & 70 & 9 & & & & & & & & & 387 \\
\hline $\begin{array}{l}\text { Indígena Pai } \\
\text { Chiquito }\end{array}$ & 99 & & & & & & & & & & & 99 \\
\hline $\begin{array}{l}\text { Tengatui } \\
\text { Marangatu }\end{array}$ & 589 & 285 & 283 & & & & & 4 & & 3 & 2 & 1166 \\
\hline TOTAL GERAL & 1526 & 614 & 611 & 27 & 73 & 3 & 1 & 11 & 55 & 5 & 9 & 2935 \\
\hline \multicolumn{13}{|c|}{$\begin{array}{l}\text { Legenda da origem étnica dos alunos: 1- Kaiová; } 2 \text { Guarani; 3- Terena; } 4 \text { Kaiová com } \\
\text { Guarani; 5- Terena com Guarani; 6- Terena com Kaiová; 7- Kaiová com não-índio; 8- Guarani } \\
\text { com não-índio; 9- Terena com não-índio; 10- Kadiwéu; 11- Não-Índio. } \\
\text { Obs. Guarani é a auto-denominação do Guarani/Ñandeva. }\end{array}$} \\
\hline
\end{tabular}

Fonte: Relação nominal dos alunos regularmente matriculados em 2006/SE/SEE/SEMED.

As diferenças étnicas, socioeconômicas e culturais manifestam-se em forma de preconceito no interior da escola. Pode ser salutar partir de dados quantitativos para se planejar ações pontuais qualitativas, buscando-se a superação das situações de conflito mais extremadas. Embora, no sistema hierárquico multiétnico da Reserva, o grupo Kaiová, em termos de indianidade, seja considerado o mais forte, de modo geral, é tido como o mais "pobre" na concepção capitalista e, freqüentemente, é discriminado, criando-se um problema de grandes dimensões sociais que se reflete diretamente na escola. Por isso, a evasão e as faltas devem ser 
dimensionadas dentro de cada contexto escolar, sem se perder de vista esses aspectos. Muitos antropólogos que já se dedicaram a estudar os Guarani, especialmente os Kaiová, costumam questionar a importância da escola para esse grupo. De fato, as maiores dificuldades dos Kaiová com a escola podem ser mais de ordem cultural do que falta de oportunidades ou barreiras lingüísticas.

Contudo, diante das novas possibilidades criadas, assistimos a um movimento muito forte desse grupo pela conquista da escola. Novas reivindicações vêm sendo formuladas e os Kaiová vêm assumindo integralmente suas escolas, como acontece, especialmente, nas escolas Araporã, Agostinho, Panambizinho e a extensão da escola Tengatuí - Francisco Ibiapina, que atendem a grande maioria dos alunos Guarani da Reserva, especialmente os daquela etnia. $\mathrm{O}$ futuro próximo poderá nos dizer se a escola será ou não algo positivo para eles e se poderá servir para melhorar sua qualidade de vida, sem deixarem de ser Guarani.

\section{Principais desafios}

Muitas são as dificuldades e as contradições suscitadas, mas gostaria de apontar 3 grandes eixos que foram estabelecidos na proposta de educação popular da SEMED como possibilidades de investimentos pedagógicos futuros também nas escolas indígenas: 1) garantir o acesso e a permanência dos alunos indígenas; 2) ampliar o acesso aos conhecimentos, o que pressupõe a efetivação de práticas específicas e diferenciadas, interculturais, bi/multilíngues e comunitárias tratadas no item anterior; 3) promover uma gestão participativa, conjuntamente com a comunidade, em todos os aspectos que dizem respeito à escola.

Para tanto, várias novas necessidades vêm surgindo em todo o processo de conquista da escola e se tornam imperiosas nos dias atuais, como a formação de professores em nível médio e superior e a formação continuada de professores e técnicos administrativos.

Formação de professores em nível médio e superior - em 2005, foi feito um levantamento na SEMED sobre o número de professores atuando na rede, buscando delinear o perfil desse professor por etnia e por nível de escolarização. Dos 115 professores atuando nas escolas indígenas, 76 eram indígenas e 39 não-índios. Dos professores indígenas, 29 eram Terena (38,4\%), dos quais 10 tinham nível superior; 28 eram Guarani/ Ñandeva (37,8\%), e apenas 7 tinham nível superior; 18 eram Guarani/ Kaiová (23,8\%), somente 2 com nível superior; e 1 era da etnia Kadiwéu, 
com nível superior. A defasagem do número total de professores da etnia Kaiová em relação ao número de alunos é extremamente desfavorável para essa etnia e a formação em nível superior é ainda mais discrepante. Dos 2935 alunos, 52\% são da etnia Guarani/Kaiová, 21\% são da etnia Guarani/Ñandeva, 20,7\% são Terena, 6 \% são mestiços ${ }^{6}$ e 0,3\% são de outra etnia ou não-índios. Os Guarani representam 72,9\% (2140) dos alunos. Se fôssemos aplicar a proporcionalidade étnica entre alunos e professores, dos 115 professores hoje existentes, 60 deveriam ser Kaiová, contra 18 existentes em 2005, 24 Ñandeva, contra 28 existentes e 24 Terena contra 29 existentes, sendo que os restantes deveriam ser os considerados "mestiços". Isso provoca sérios desequilíbrios internos, seja no atendimento aos alunos, que são, em sua maioria, Kaiová falantes da língua e que precisariam de professores qualificados para tanto, inclusive para o controle político da escola; no caso da Escola Tengatuí, mesmo com a criação das Escolas Agostinho, Araporã e do Panambizinho como escolas independentes, continua sendo a maior escola da Reserva, com $2 / 3$ de alunos Guarani. Esse equilíbrio político vem se dando a partir de 2004 , com a criação dessas escolas, onde toda a organização administrativa e pedagógica tem sido realizada pelos professores Guarani e as respectivas comunidades escolares, embora ainda majoritariamente por professores da etnia Nãndeva, o que causa discrepâncias em relação aos Kaiová. Dedido à falta de professores, os professores indígenas compõem com professores não-índios, especialmente para atuar na segunda etapa do ensino fundamental ( $5^{\mathrm{a}}$ a $8^{\mathrm{a}}$ série). Procura-se encontrar professores Guarani, seja Nãndeva ou Kaiová, no interior da própria Reserva e até mesmo em outras Reservas que tenham escolaridade mínima.

O equilíbrio étnico do poder dentro da Reserva se faz imprescindível. As disparidades tendem, momentaneamente a se dilatar, em razão do oferecimento de $5^{\mathrm{a}}$ a $8^{\mathrm{a}}$ série dentro das escolas da Reserva. Isso deve ser monitorado pela SEMED, acompanhado de uma política de formação de professores em nível superior.

De modo geral, há um reconhecimento de que o professor nãoíndio só deve atuar nas escolas indígenas na falta de professores indígenas. Uma das exceções fica por conta da escola Agostinho, que mantém em seus quadros antigos professores da FUNAI, que detêm a simpatia de uma parcela dos pais; também porque existe ali uma certa cristalização da idéia de que o ensino em português desde a fase inicial seria mais proveitoso. A outra seria a escola Francisco Meireles que atua em parceria com a Missão Evangélica Caiuá.

A reivindicação por uma formação em nível superior específico, que se iniciou com o movimento de professores Guarani/Kaiová, está 
em vias de ser atendida pela Universidade Federal da Grande Dourados (UFGD), em parceria com o MEC, depois de um longo processo de discussões efetuadas, inicialmente, com a Universidade Estadual do Mato Grosso do Sul (UEMS). A proposta vem sendo reivindicada pelas demais etnias existentes no estado, como os Terena, Atikum, Kamba, Ofaié, Kinikinawa, Kadiwéo e Guató.

Formação continuada de professores e técnicos administrativos visa a instrumentalizar as escolas para promover sua organização segundo parâmetros próprios, o que já vem sendo realizado pela SEMED sistematicamente, tanto em relação às questões administrativas quanto pedagógicas, mas esbarra nos limites da formação inicial desses professores. No projeto político pedagógico que se encontra em processo de elaboração, torna-se imperiosa a adoção de uma política lingüística da parte de cada escola, segundo suas particularidades. Esse processo deverá contar com assessorias externas sistemáticas, de modo a desenvolver-se adequadamente.

Desse modo, entendo que todos os envolvidos no processo deverão somar esforços no sentido de encontrar caminhos metodológicos para subsidiar a prática dos professores em suas escolas, buscando conciliar as especificidades de cada realidade com as concepções universais. Diante de situações diferenciadas, como pensar na escola enquanto campo de difusão de conhecimentos indígenas (fundamentalmente de tradição oral) e não-índígenas (fundamentalmente baseados na cultura escrita), de forma a valorizar todos os conhecimentos como premissa da interculturalidade, sem depreciar os conhecimentos indígenas tradicionais? Em consonância com as reflexões suscitadas em um curso realizado na Reserva de Caarapó, com Dominique Gallois ${ }^{7}$, é preciso ir-se processando essa escola devidamente alicerçada em pressupostos teóricos consistentes, das várias áreas do conhecimento, quanto a conhecimento formal/não formal, oral/escrito, compreendendo-se como fundi-los apropriadamente para se construir um currículo adequado para a escola indígena.

Não é todo o conhecimento que vai para a escola e nem tampouco para a escrita. Esta poderá constituir-se em um instrumento de formalização e sistematização, mas o que vai garantir a valorização e fortalecimento dos conhecimentos é, antes de tudo, a vivência, a sua capacidade de responder às necessidades da comunidade. É a busca do entendimento dos significados de cada palavra, de cada contexto. A reza, por exemplo, é um jeito de falar alguma coisa (conteúdo) de um modo certo, segundo os sentimentos, o simbolismo de um dado grupo social. A grande preocupação que deve permear o trabalho do professor na escola é juntar forma e conteúdo; ele deve se preocupar mais em como fazer do que no 
que fazer; por exemplo, usar sempre a língua materna, porque, na segunda língua, o sentido poderá ser comprometido e assumir significados diversos. O uso da segunda língua, nos primeiros anos da escola, poderá comprometer irremediavelmente os significados das palavras e esvaziar o seu verdadeiro sentido cultural. A questão da fragmentação do conhecimento também deverá ser uma preocupação constante na formação de professores indígenas. Como evitar que, a partir do momento em que se retira parte do conhecimento indígena tradicional para se levar para a escola, este esteja sendo esvaziado de seus substratos culturais mais profundos, perdendo o sentido de totalidade e, mais do que isso, prescindindo da forma, do jeito, do modo de ser da cultura, do significado mais profundo das palavras e das coisas? Estes são desafios imensos que deverão ser tratados com muita responsabilidade.

Em consonância com Dominique Gallois (2004), pensamos que o caminho mais consistente a seguir é respeitar o papel de cada um na sociedade indígena, ou seja, o professor não poderá processar a reza, mas poderá entendê-la, explicá-la, levar, pois, para a escola a teoria da reza, a qual, uma vez apreendida, poderá fazer o caminho de volta para ser vivenciada. A teoria/sistematização dos conhecimentos indígenas selecionados para serem levados para a escola é o jeito que temos de explicar os fenômenos culturais para confrontá-los com os conhecimentos não-indígenas.

Gostaria, ainda, de comentar a experiência da roça Kaiová, projeto proposto pela comunidade do Panambizinho, desenvolvido a partir de agosto de 2005, como exemplo criativo que reúne parceiros em busca da efetivação do que se tratou acima. Depois dos encaminhamentos e sugestões dos técnicos da SEMED, os estudantes reuniram-se com os pais e lideranças para selecionar o que plantariam e como plantariam. Vários participantes responsabilizaram-se por trazer mudas dos vários tipos de mandioca, batata doce, milho e feijão; foi feita a divisão sexual do trabalho, respeitando-se os elementos místicos e religiosos que permeiam todo o ritual de plantação, o mesmo acontecendo com a colheita, culminando com a festa da colheita, elemento fundante da cultura Kaiová. Os mais velhos propuseram-se a explicar todo o processo aos alunos, segundo os conhecimentos Kaiová e seu sentido cultural. Esse processo passou por uma seleção/teorização/sistematização dos conhecimentos tradicionais e toda a prática realizada serviu de conteúdo para algumas aulas promovidas pelos professores indígenas e não-indígenas, sendo que estes últimos dedicaram-se a explicar os conhecimentos das técnicas não-indígenas introduzidas na experiência, num trabalho interdisciplinar. O projeto, em fase embrionária, sofreu alguns reveses de ordem burocrática, mas, 
por iniciativa da própria comunidade escolar, está sendo redimensionado com o suporte disponível no momento. Em relação à realidade de Dourados, isso deverá ser processado pela comunidade escolar, segundo as culturas Guarani e Terena, ou, mais precisamente, a partir de uma comunidade multiétnica.

Para avançar esse processo, é preciso não apenas subsidiar os professores nessa tarefa, papel fundamental das agências formadoras, mas, antes de tudo, interagir com eles, promovendo, de fato, a interculturalidade.

\section{Notas}

${ }^{1}$ Ver por exemplo BRITO, S.H.A. Escola e Movimento Indigenista no Brasil: da educação alternativa para o índio à educação escolar indígena (1970-1994). Dissertação (Mestrado em Educação) - UFMS/ Campo Grande/MS, 1995; FERREIRA, M. K. Da origem dos homens à conquista da Escrita: um estudo sobre povos indígenas e educação escolar no Brasil. Dissertação (Mestrado em Antropologia Social) - USP/SP, 1992; CIMI (Conselho Indigenista Missionário). Com as próprias mãos: professores indígenas construindo a autonomia de suas escolas. Brasília, 1992; EMIRI, L; MONSERRAT, R. (Orgs.). A Conquista da Escrita. OPAN - Operação Anchieta. Ed. Iluminuras, 1989; SILVA, R.H.D. A autonomia como valor e a articulação de possibilidades: um estudo sobre o movimento de professores indígenas do Amazonas, Roraima e Acre, a partir de seus Encontros anuais. Tese (Doutorado em Educação) - USP/SP, 1997; LEITE, A. G. O. Educação Indígena Ticuna: Livro Didático e Identidade Étnica. Dissertação (Mestrado em Educação) - UFMT/ Cuiabá/MT, 1994, entre outros.

${ }^{2}$ Além dos trabalhos citados na nota anterior, ver especialmente o trabalho de NASCIMENTO, Adir Casaro. Educação Escolar Indígena: em busca de um conceito de educação diferenciada. Tese (Doutorado em educação) - UNESP/Campus de Marília/SP, 2000.

${ }^{3}$ Essa compreensão foi retirada da nossa dissertação de mestrado, intitulada Por uma nova textura histórica: o movimento de professores Guarani/Kaiová em Mato Grosso do Sul - 1988-2000, que compôs uma síntese das anotações referentes aos debates processados durante o I Encontro de Educação Escolar Indígena da América Latina, realizado em Dourados, de 23 a 27 de março de 1998 e nos referenciais de alguns autores como os que foram explicitados na nota 2.

${ }^{4}$ O termo vem sendo utilizado desde as primeiras décadas do século XX, em decorrência da política do S.P.I. em promover a entrada de elementos não-indígenas, inclusive em condições privilegiadas, sendo designados para o cargo de Capitão ou mesmo de apoio ao chefe do Posto, visando favorecer a mestiçagem e, com ela, uma integração mais rápida e eficaz. $\mathrm{O}$ termo acabou sendo utilizado como categoria nativa, por vezes pejorativa, para identificar quem não está vinculado a nenhum desses grupos. ${ }^{5}$ Os dados referentes ao número de alunos no período do S.P.I. e FUNAI não estão disponíveis no momento. Existem alguns dados do primeiro período, mas só da escola mantida pelo S.P.I.; não se dispõe dos dados da Escola da Missão. No segundo período, dispõe-se dos dados da Missão e não da FUNAI, o que impede uma 
análise comparativa. A partir da municipalização de todas as escolas da FUNAI, foi possível o levantamento do número de alunos, o que aconteceu depois de 1992. ${ }^{6}$ Há que se ressaltar que o número real de "mestiços" pode ser bem maior, uma vez que as informações colhidas foram tiradas dos registros de nascimentos, que são muitas vezes incorretas. Por exemplo, quando os pais são de etnias diferentes, é comum privilegiar a etnia do pai no registro de nascimento. Dos números em questão, os mestiços entre índios somam 100 alunos e com não-índios somam 67 alunos.

${ }^{7}$ Curso sobre currículo realizado na Escola Indígena da Reserva de Caarapó/MS, em 29 de setembro de 2004.

\section{Referências}

GALLOIS, Dominique. Apontamentos da oficina "saberes Indígenas e Currículo". Escola Indígena. Caarapó-MS, setembro de 2004.

MELIÁ, Bartomeu. Educação Indígena e alfabetização. São Paulo: Loyola, 1978.

Ação pedagógica da diferença. In: CONGRESSO INTERNACIONAL DE EDUCAÇÃO ESCOLAR INDÍGENA. Dourados, 1998 (Texto não publicado).

NASCIMENTO, Adir Casaro. O princípio da eqüidade da educação básica brasileira: as particularidades da realidade educacional de Mato Grosso do Sul. In: MARIN, Jérri Roberto; VASCONCELOS, Cláudio Alves de (Orgs.). História, região e identidades. Campo Grande: UFMS, 2003.

BRASIL. Constituição da República Federativa do Brasil.16 ed. São Paulo: Saraiva, 1997.

. Ministério da Educação e Cultura. Diretrizes para a política nacional de educação escolar indígena. v.2, 1994 (Série Institucional - Cadernos Educacionais).

. Ministério da Educação e Cultura. Referencial Curricular para as escolas indígenas. Brasília: Secretaria de Educação Fundamental, 1998.

\section{Documentos gerais:}

Censo escolar da Secretaria Municipal de Educação referente aos anos de 1992, 2001, 2002, 2003, 2004, 2005, 2006.

Justificativa da Secretaria Municipal de Educação enviada ao Conselho Estadual de Educação, 05/05/1997.

Ofício n. 21 de abril de 1928 confirmando relatório referente ao ano de 1927. Museu do Índio, Mf 194, fotograma 29/30.

Relatório Constituinte Escolar da Secretaria Municipal de Educação, 2003.

Relatório Posto Indígena Francisco Horta, 9/12/1937, Mf 194, fotograma 171.

Relatório I Encontro de Professores Guarani/Kaiová de MS, 1991.

Várias provas, junho de 1965. Museu do Índio, Mf 7.

Várias provas, 1966. Museu do Índio, Mf 7.

Recebido em 25 de julho de 2006.

Aprovado para publicação em 23 de agosto de 2006.

Tellus, ano 6, n. 11, out. 2006 
